\title{
Prevotella intermedia
}

National Cancer Institute

\section{Source}

National Cancer Institute. Prevotella intermedia. NCI Thesaurus. Code C86670.

A species of obligately anaerobic, Gram-negative, rod shaped bacteria assigned to the phylum Bacteroidetes. This species is nonmotile, non-spore forming, pigmented, sucrose and indole positive, but xylose, arabinose, cellobiose, rhamnose, salicin, lactose, esculin hydrolysis, beta- $\mathrm{N}$-acetyl-glucosaminidase, beta-glucosidase and glycine aminopeptidase negative. P. intermedia is found in ging ival crevices where it can cause ging ivitis, chronic periodontitis, and other infections of the oral cavity, but is also associated with abscesses and a variety of systemic infections. 